\title{
Hardware-in-the-loop simulator of wind turbine emulator using labview
}

\author{
Himani, Navneet Sharma \\ Department of Electronics and Communication, ABES Engineering College, India
}

\begin{tabular}{l}
\hline Article Info \\
\hline Article history: \\
Received Oct 10, 2018 \\
Revised Oct 27, 2018 \\
Accepted Mar 1, 2019 \\
\hline
\end{tabular}

Keywords:

DC motor

Hardware In the Loop

LabVIEW

Wind turbine emulator (WTE)

Wind Turbine(WT)

\begin{abstract}
This paper describes the design and implementation of Hardware in the Loop (HIL) system D.C. motor based wind turbine emulator for the condition monitoring of wind turbines. Operating the HIL system, it is feasible to replicate the actual operative conditions of wind turbines in a laboratory environment. This method simply and cost-effectively allows evaluating the software and hardware controlling the operation of the generator. This system has been implemented in the LabVIEW based programs by using Advantech- USB-4704-AE Data acquisition card. This paper describes all the components of the systems and their operations along with the control strategies of WTE such as Pitch control and MPPT. Experimental results of the developed simulator using the test rig are benchmarked with the previously verified WT test rigs developed at the Durham University and the University of Manchester in the UK by using the generated current spectra of the generator. Electric subassemblies are most vulnerable to damage in practice, generator-winding faults have been introduced and investigated using the terminal voltage. This wind turbine simulator can be analyzed or reconfigured for the condition monitoring without the requirement of actual WT's.

Copyright (C) 2019 Institute of Advanced Engineering and Science. All rights reserved.
\end{abstract}

\section{Corresponding Author:}

Himani,

Departement of Electronics and Communication Engineering,

ABES College of Engineering, Ghaziabad, India.

Email: himani.garg@abes.ac.in

\section{INTRODUCTION}

Over the decades, the wind turbines (WT) became the swiftest evolving renewable energy technology. The control of the WT becomes important with the increase in the power level of the turbines. To achieve high performance and high efficiency in power systems, Power electronic plays a vital role in wind power systems[1-2]. Operational and maintenance cost are the most important factors for the technological progress of the wind turbine(WT) systems [3]. Figure 1 presents the failure rate of wind turbine components [4]. The repair and maintenance of the WT electrical components can be very costly if the faults lie unnoticed [1].

Inter-turn short circuit faults in the stator accounts for a substantial percentage of all the possible faults occurred in wind turbine generator [4-6]. In a very short time, disastrous damage to the machine can be caused [4-7]. Therefore fault should be quickly detected using the condition monitoring. The evaluation of the fault diagnosis process on the actual wind turbine may damage the complete system. Therefore, for CM evaluation, wind turbine test rig is required to emulate wind energy conversion systems [7-8]. In the most of the earlier research, test rigs are controlled by aerodynamic forces using wind turbine emulator [9-11], speed control by PLC [12], analog inputs [13] and wind tunnel [14].

For a given wind velocity, wind turbine emulator (WTE) generates same energy and torque as generated by actual WT [7-8]. The WTE consists of two mechanically coupled electrical machines, with the 
wind torque is imitated by the motor and other machines can be used as generator M1 imitating, and M2 stand-in as a generator [7-9].

For the growth of wind energy conversion systems (WECS), HIL (Hardware-in-the-Loop) simulation is an essential kit. The concept of a hardware-in-the-loop simulation system is to replace the physical systems with the simulation platform. Through an interface, this platform makes a closed loop system with the real devices. Without the need of real wind turbine or natural wind resources, this system reproduces the WT characteristics both steady state and dynamic features in a coordinated environment. The emulator drives an electrical generator like WT, by replicating the torque settled by a WT. Also, it can be developed as an educational tool to illustrate the operation, behavior, and control of a WT [15-22].

The principal objective of this research paper is the development of HIL simulator for the development of test rig. The real-time HIL simulator for control and monitoring the test rigs are developed in the LabVIEW which control the prime mover as per WT norms and follows the speed-torque features of the WT.This output of the test rig is benchmarked with the proven test rigs [18-21] by analyzing the generated current spectra. With HIL simulator, short circuit fault has been analyzed in the test rig using the FFT analysis.

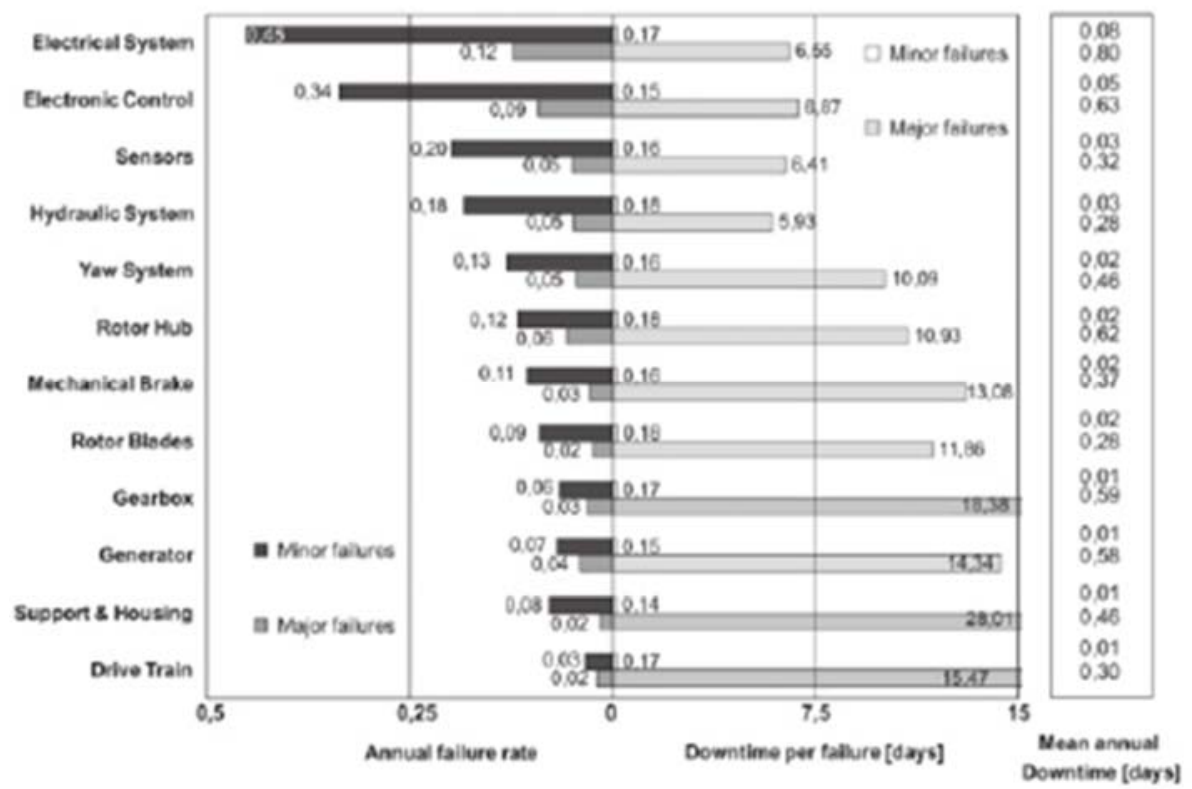

Figure 1. WT Distribution of failures data

\section{WIND TURBINE EMULATOR MODEL}

To imitate the wind turbine, the test-rig was with the specifications as mentioned in Table 1. The block diagram and experimental setup of the test rig are illustrated in Figure 2 and Figure 3 [19, 23-24].

Table 1. Parameters of wind turbine

\begin{tabular}{lc}
\hline \multicolumn{1}{c}{ Specifications } & Value \\
\hline Rated power & $800 \mathrm{Watts}$ \\
Rated wind Speed & $7.5 \mathrm{~m} / \mathrm{sec}$ \\
Radius of WT & $1.5 \mathrm{~m}$ \\
Power coefficient & 0.49 \\
WT inertia coefficient (min-max) & $0.08 \mathrm{kgm} 2-0.18 \mathrm{kgm} 2$ \\
Optimum power coefficient $\left(\beta=0^{\circ}\right)$ & 0.412 \\
Optimum TSR $\left(\beta=0^{\circ}\right)$ & 8 \\
Generator type & $\mathrm{SCIG}$ \\
Drivetrain & Direct \\
\hline
\end{tabular}

Int J Pow Elec \& Dri Syst, Vol. 10, No. 2, June 2019 : 971 - 986 


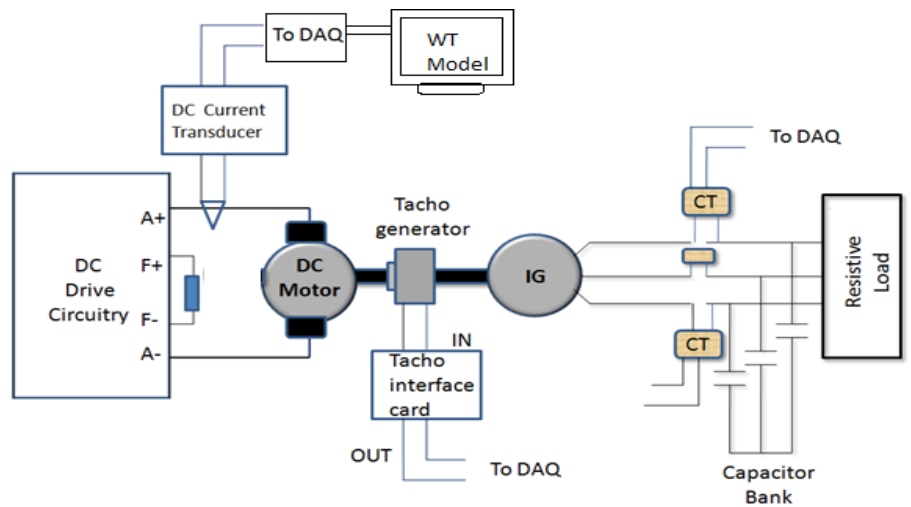

Figure 2. Experimental setup-Block diagram

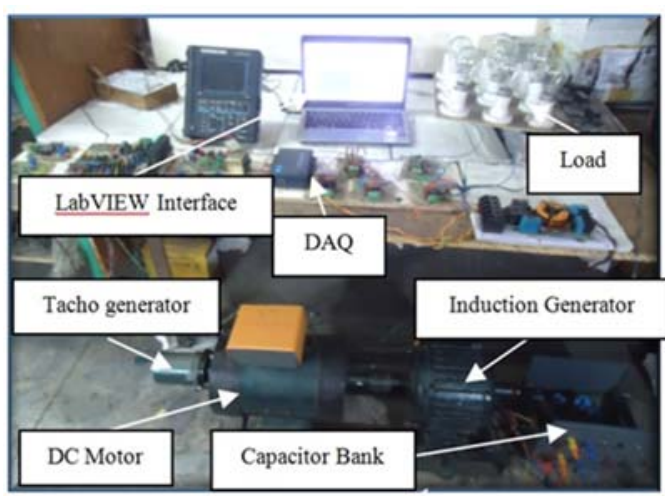

Figure 3. Actual Experimental setup

\section{WIND TURBINE AERODYNAMIC MODEL}

The accessible wind power of a WT with length L, radius $R$, , air density $\rho$, swept area A, power coefficient $C_{p}$ and wind speed $v$ is given by[9,17-19]:

$$
\mathrm{P}=1 / 2 \rho v^{3} \mathrm{C}_{\mathrm{p}} \mathrm{A}
$$
specified as

Power coefficient is the function of tip speed ratio $(\lambda)$ with $\omega$ is the rotor angular velocity, which is

$$
\lambda=\mathrm{R} \omega / \mathrm{v}
$$

$C_{p}-\lambda$ relationship are presented in Figure 4 [11].

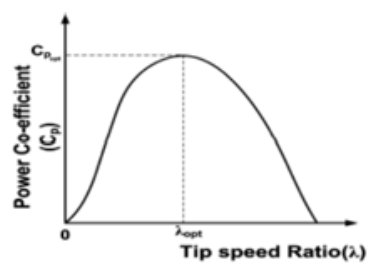

Figure 4. Power Co-efficient and Tip speed ratio characteristics of a WT 
The numerical approximation of the power coefficient can be computed as [11-14]:

$$
C_{p}(\lambda, \beta)=C 1\left(C 2 / \lambda_{i}-C 4-C 3 \beta\right) e^{-C 5 / \lambda i}+C 6 \lambda
$$

The mechanical torque produced can be computed from the shaft speed and WT power and as given by [11-14]:

$$
\mathrm{T}_{\text {wind }}=\frac{1}{2 \lambda} \rho \pi \mathrm{v}^{2} \mathrm{R}^{3} \mathrm{C}_{\mathrm{p}}
$$

The WT dynamic model can be illustrated as

$$
\mathrm{J}_{\mathrm{r}} \frac{\mathrm{d} \omega_{\mathrm{r}}}{\mathrm{dt}}=\mathrm{T}_{\text {wind }}-\mathrm{T}_{\text {gen }}-\mathrm{T}_{\mathrm{rf}}
$$

Where $\mathrm{T}_{\text {gen }}$-the generator torque,

$\mathrm{T}_{\mathrm{rf}}$ - the rotor friction torque,

$\mathrm{J}_{\mathrm{r}}$ - the equaling interia of the rotor.

\section{HARDWARE-IN-THE-LOOP (HIL) SYSTEM}

Graphical illustration of the WT and HIL systems are presented in the Figure 5. The HIL system is made to equipped with $220 \mathrm{~V}, 1.5 \mathrm{~kW}$ induction machine as the prime mover, a $2.5 \mathrm{~kW}$ separately excited D.C motor. For data acquisition card, Advantech 4704 is used as an interface between hardware and software (LabVIEW).

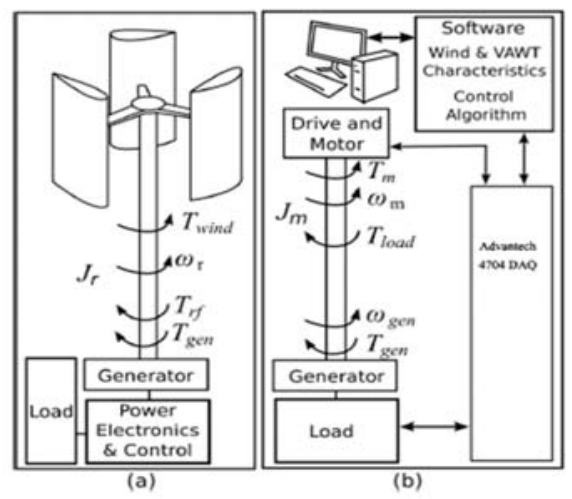

Figure 5. (a) Representation of WT systems, (b) HIL simulator system

Figure 5 (a) [15-16] presents the dynamics of the WT system. The similar dynamic behavior can be imitated by the HIL system:

$$
\mathrm{J}_{\mathrm{m}} \frac{\mathrm{d} \omega_{\mathrm{m}}}{\mathrm{dt}}=\mathrm{T}_{\mathrm{m}}-\mathrm{T}_{\text {load }}
$$

Where $\mathrm{J}_{\mathrm{m}}$ is the corresponding inertia at the motor side, $\mathrm{T}_{\mathrm{m}}$ is the motor torque, $\omega_{\mathrm{m}}$ is the rotational speed of the motor shaft, and the total load torque, $\mathrm{T}_{\text {load }}$ is specified as:

$$
\mathrm{T}_{\text {load }}=\frac{\mathrm{T}_{\text {gen }}}{\tau}+\mathrm{T}_{\mathrm{hf}}
$$

Where $\tau$ is the gear ratio, $\mathrm{T}_{\text {gen }}$ is the torque of the generator, and $\mathrm{T}_{\mathrm{hf}}$ is the friction torque. The rotational speed of the generator, $\omega_{\text {gen }}$, is linked to the motor speed by (8)

Int J Pow Elec \& Dri Syst, Vol. 10, No. 2, June 2019 : 971 - 986 


$$
\omega_{\text {gen }}=\frac{\omega_{\mathrm{m}}}{\tau}
$$

With the assumption that the generator is directly coupled to the rotor and the WT with no gearbox, the rotational speed of the rotor would be similar to as the rotational speed of the generator in the HIL system as:

$$
\omega_{\mathrm{r}}=\omega_{\mathrm{gen}}
$$

The performance of the WT system, with the suitable motor torque $\mathrm{T}_{\mathrm{m}}$, can be imitated by the HIL simulator. From the (4)-(8) the reference torque in the simulator can be computed as:

$$
\mathrm{T}_{\mathrm{m}}=\mathrm{T}_{\text {load }}+\frac{\mathrm{J}_{\mathrm{m}} \tau}{\mathrm{J}_{\mathrm{w}}}\left(\mathrm{T}_{\text {wind }}+\mathrm{T}_{\mathrm{rf}}-\mathrm{T}_{\text {gen }}\right)
$$

The representation of the HIL system and WT system are presented in Figure 6 where for imitating the rotor dynamics, the motor is used as an actuator.

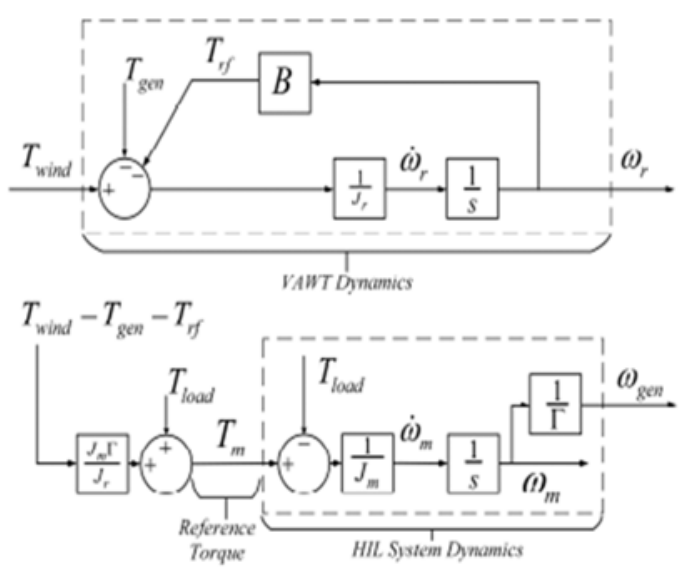

Figure 6. Representation of the HIL System, WT dynamics, and reference motor torque calculation

\section{THE CONTROL ALGORITHM}

To calculate the frequency of wind speed in the various ranges, the subprogram was developed as shown in Figure 7. To calculate the value of the power created by the WT as described in (1), the subprogram is shown in Figure 8.

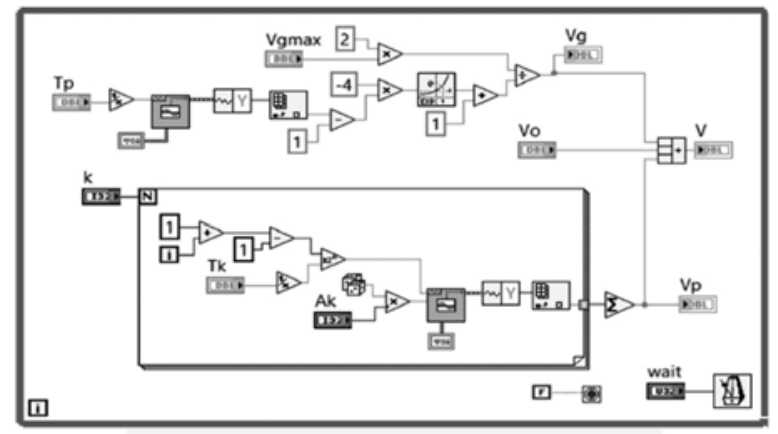

Figure 7. A subprogram producing the wind speed variability in LabVIEW 


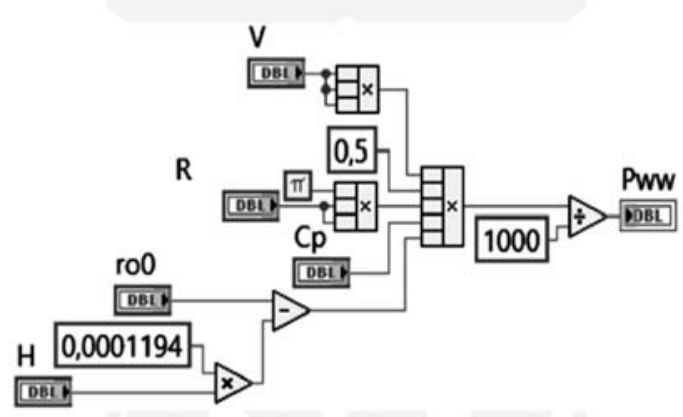

Figure 8. A subprogram measuring the power produced by the wind turbine in LabVIEW

The power coefficient as defined in the equation (3), the VI as shown in Figure 9, which is interfaced with the test rig using DAQ was developed in the LabVIEW. The VI block as presented in the Figure 10 filters the high harmonic contents in the real-time current signal. The PI control is implemented in the LabVIEW. PI controller tunes the error in the current by comparing the reference current with the actual current. The PI with a reference point control as:

$$
u(t)=K_{p} e(t)+K_{i} \int_{0}^{t} e(t) d t
$$

Where:

$\mathrm{u}(\mathrm{t})$ is actuating signal

$\mathrm{K}_{\mathrm{p}}$ is proportional gain

$\mathrm{K}_{\mathrm{i}}$ is integral gain

$\mathrm{e}(\mathrm{t})$ is error signal

The Laplace transform of the actuating signal integrating in proportional plus integral control is

$$
U(s)=K_{i} \frac{E(s)}{s}+K_{p} E(s)
$$

The PI control of D.C Motor system with the closed loop system is presented in Figure 10. Both reference current and actual current are compared and then applied to PI controller. By using the proportional gain, $\mathrm{K}_{\mathrm{p}}$ in an interactive fashion, tuning the controller for optimal performance was done manually. In a similar way, integral gain $K_{i}$ was chosen to reduce the steady-state error to zero. The control environment then communicates a control signal, $0-10 \mathrm{~V}$ related to current demand, to the variable speed D.C drive in real time.

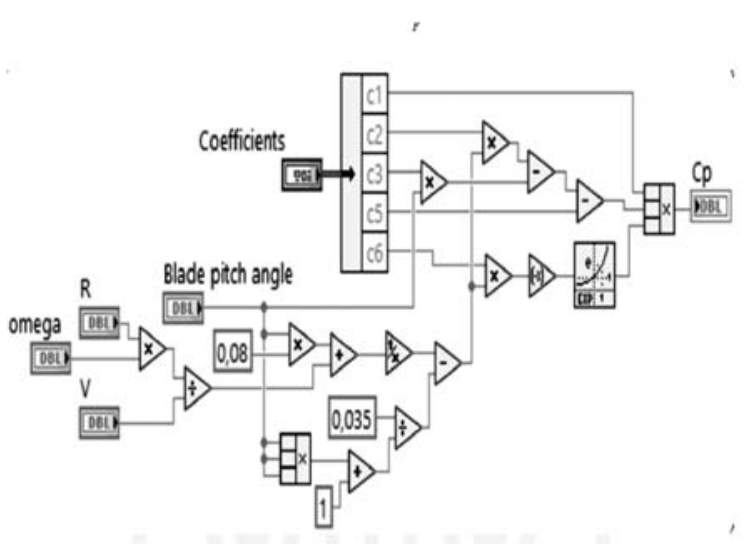

Figure 9. The subprogram calculating the coefficient $\mathrm{Cp}$ 


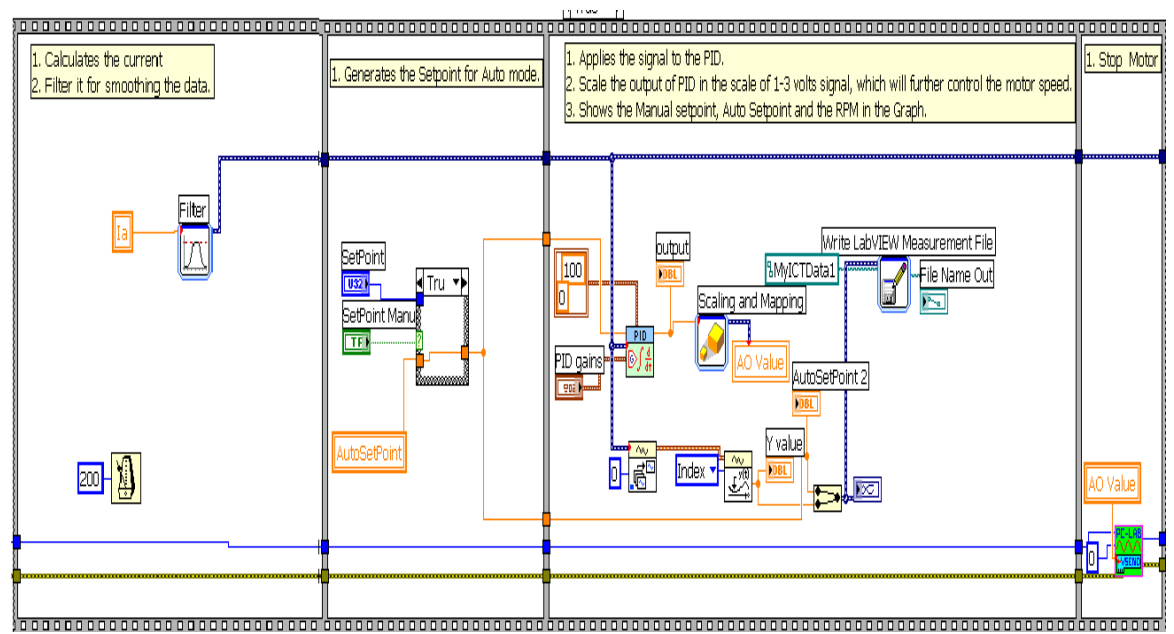

Figure 10. LabVIEW interface for Digital PI Controller, Current filter block

To control the speed of the D.C motor, a thyristor-based D.C drive has been used. D.C drive can operate as a four-quadrant drive and allows torque control and/or speed control of a D.C motor. By maintaining constant field current and controlling the armature current, it allows controlling the speed of the D.C motor. Figure 11 shows the control schema of D.C drive. By using the LabVIEW PI, speed demands are converted into the current demands.

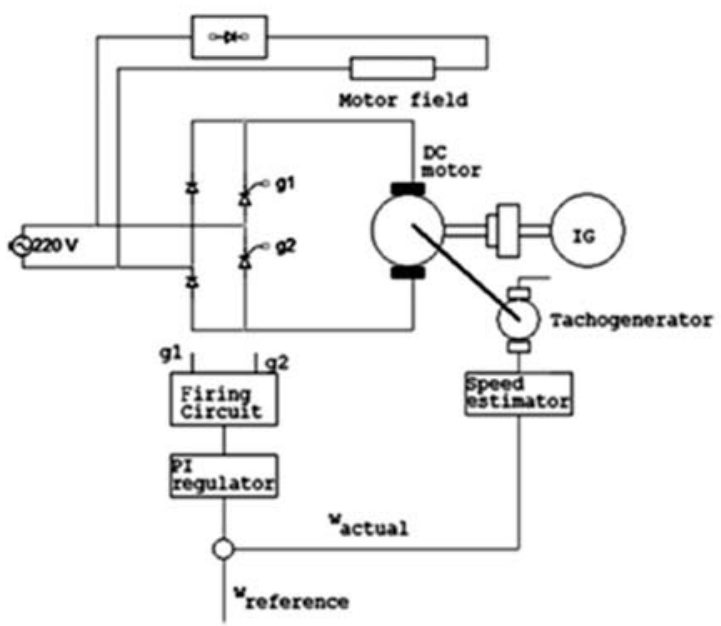

Figure 11. Control schema of D.C drive

The real-time code is also written in the LabVIEW which acknowledges the interrupt and transfers the output into the output channel as shown in Figure 12. For armature voltage regulation, the inputs to the full wave half controlled rectifier circuit are the controlled signals from the developed LabVIEW VI's. By switching ON the relay through digital output control of DAQ, the operations of the motor are started. The real-time data inputs like D.C motor speed and current as seen in Figure 13 are acquired by generating an interrupt. Beginning from left to right, the simulation executes sequentially, from source to sink block. This process is iterated over the desired time period using the operator defined time step. Beginning the process, the simulation retrieves the shaft speed of the generator from the tacho-generator over the DAQ channel. The high harmonic contents in the real-time speed signal are filtered by the LPF filter as shown in Figure 14 and then the filtered speed is fed into the WT model. Based on the user requirements, the test rig can be controlled at either constant or variable speed. The results in this research are restricted to two variable speed 
driving conditions demonstrating known WT driving conditions. To reduce the volume of data recorded, the number of different driving conditions was kept to a minimum.

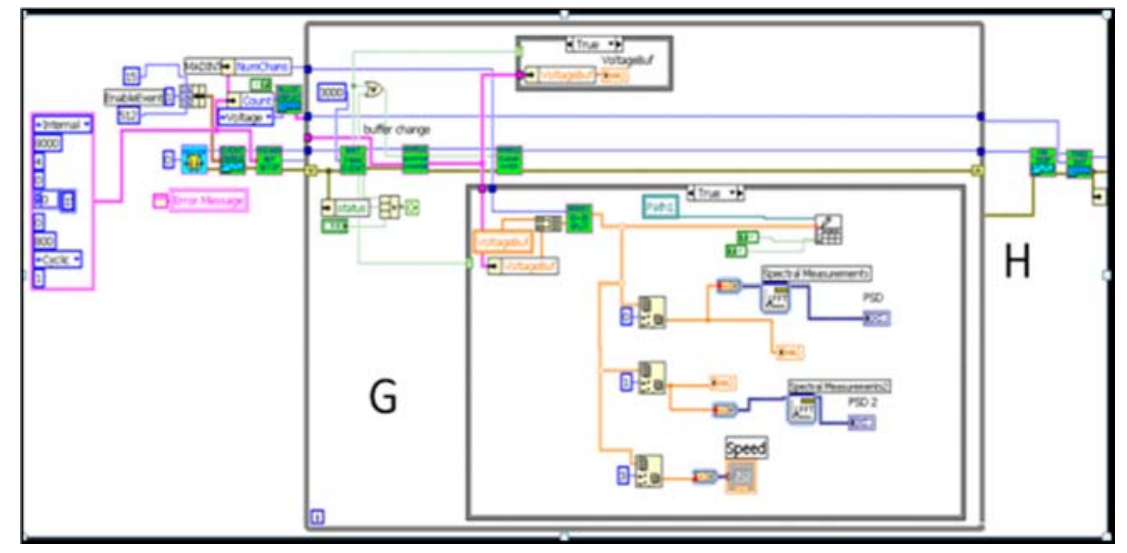

Figure 12. LabVIEW interface for write-output and acknowledge interrupt

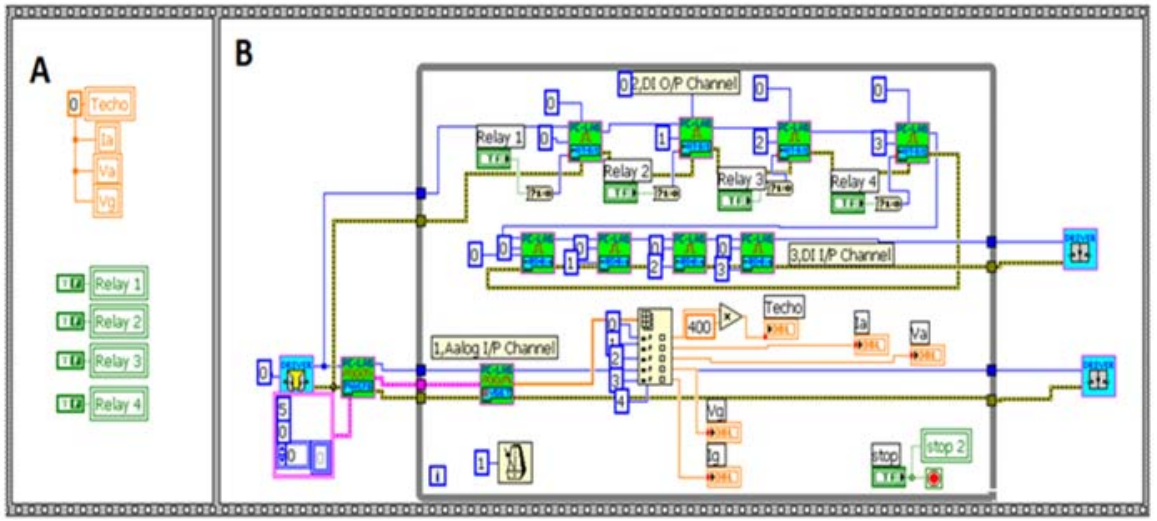

Figure 13. LabVIEW VI for interrupt inputs

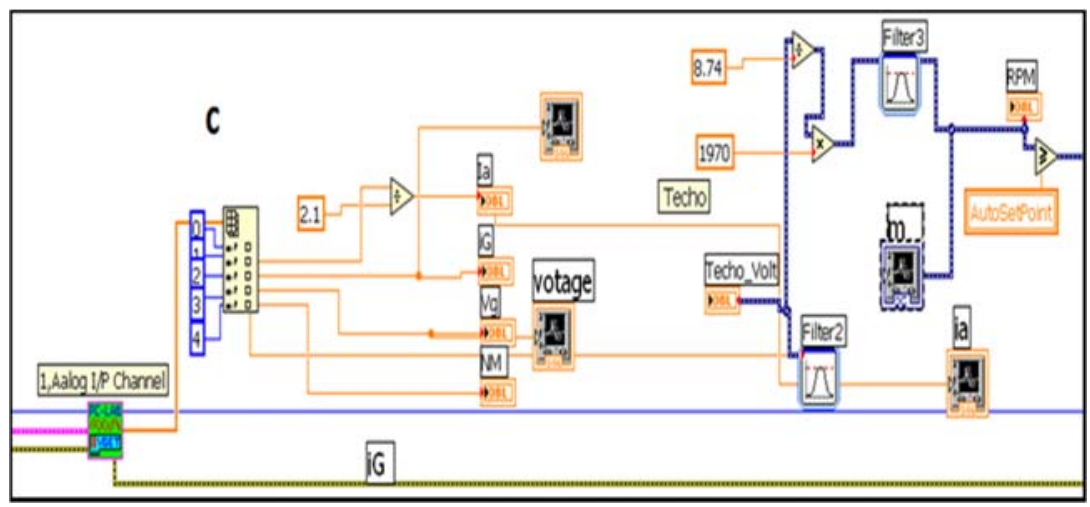

Figure 14. LabVIEW VI for Speed filter block 
For real-time communication between the user and WTE test rig, the control panel as presented in Figure 15 developed in LabVIEW. The User can constitute various parameters of WTE such as WT Radius, Wind speed, Motor ON/OFF, Proportional Integral Gain, Speed Control and integration of Microsoft office for data storage. The control schema as illustrated in the Figure 16 that has been implemented includes MPPT using a chopper controlled circuit, modeling of WT in LabVIEW, and pitch control scheme using a PI controller. If the WTE works at the optimum tip speed ratio, maximum power can be obtained from the emulator for a constant wind speed. By comparing the actual tip speed ration with the optimum tip speed ratio, MPPT control logic generates the gate pulses using the PWM technique. The main task of the hardware in the loop simulator developed in the LabVIEW is to establish the bi-directional communication with the machine; acquirement of terminal voltage and generator current, calculation of tip speed ratio, $\mathrm{C}_{\mathrm{p}}-\lambda$ curves, implementation of MPPT and TSR algorithms, computation of pitch angle and generated electric power as per the wind speed data. Figure 17 presents the schematic layout of the interface circuit established in LabVIEW. The comparison of the actual current with the reference current is presented in Figure 18.
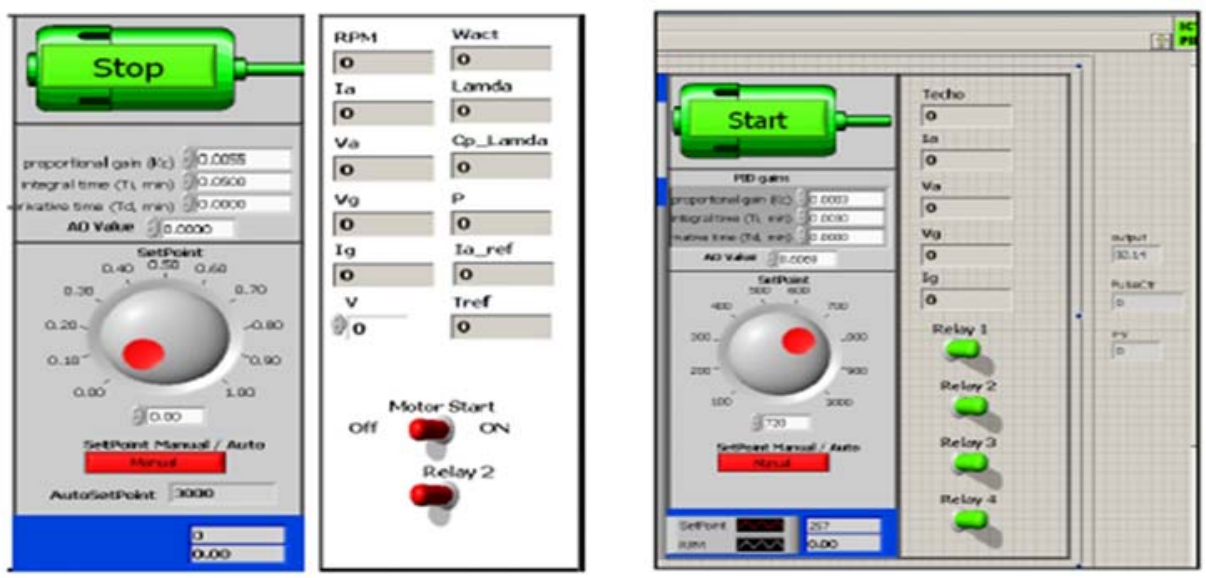

Figure 15. Control Panel

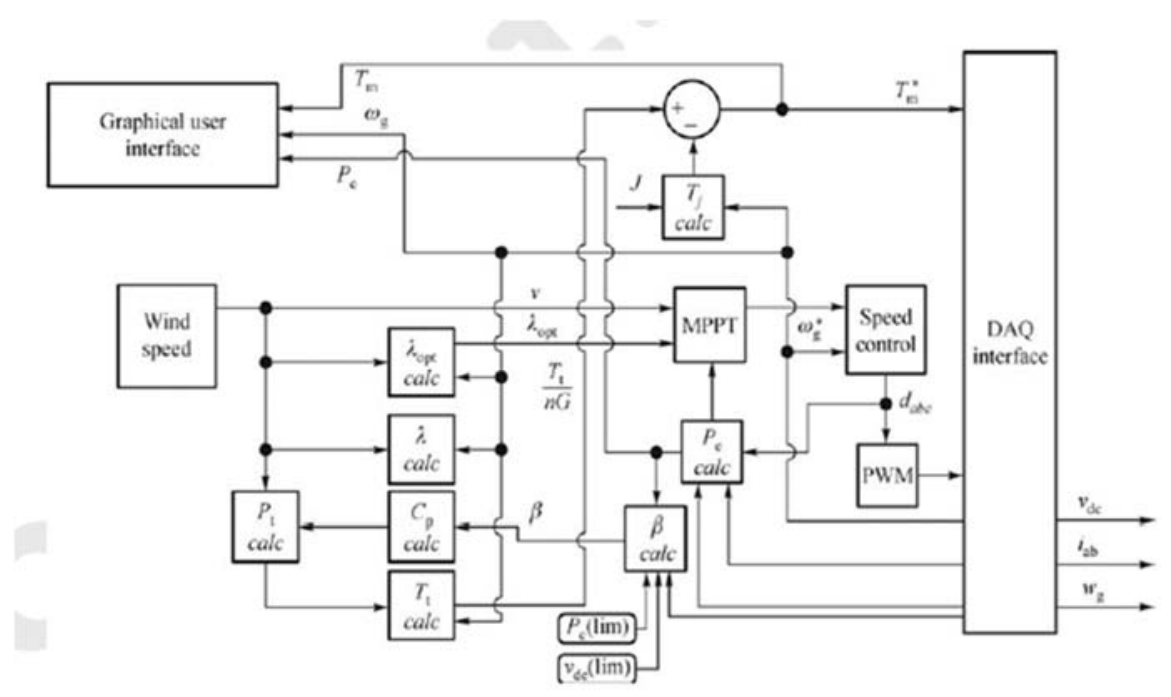

Figure 16. Block diagram of the control schema 


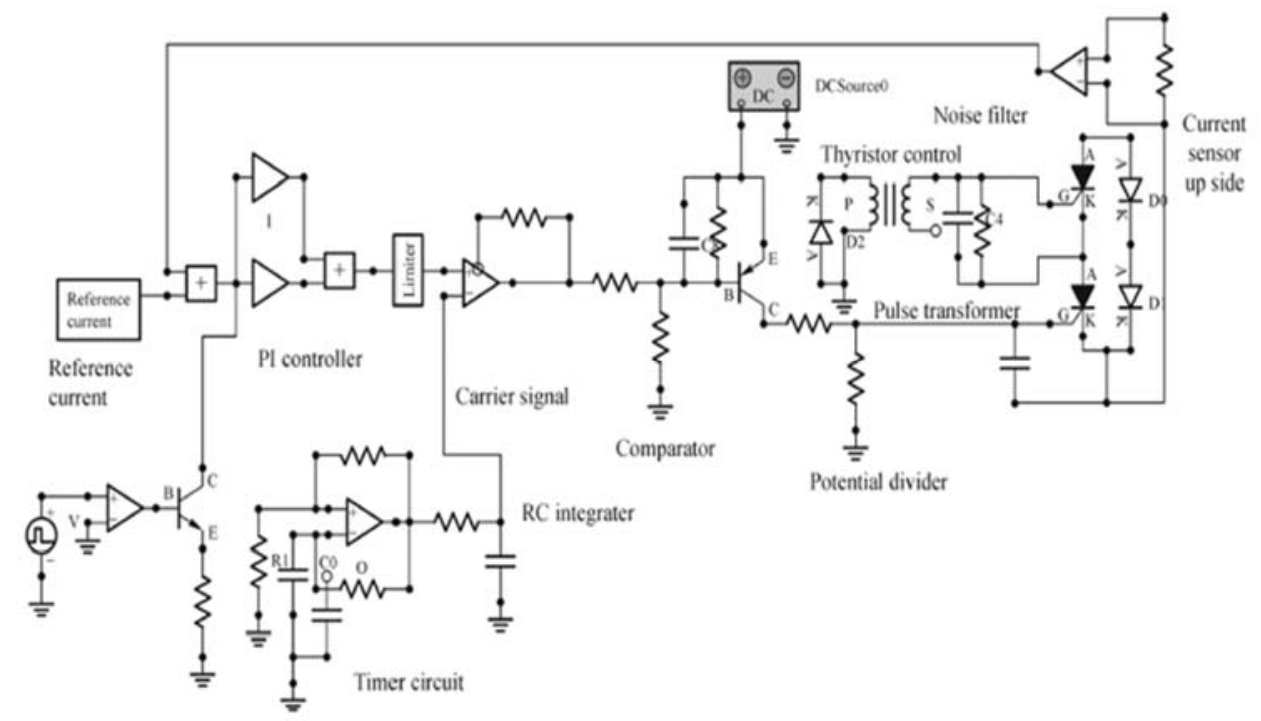

Figure 17. Current control circuit

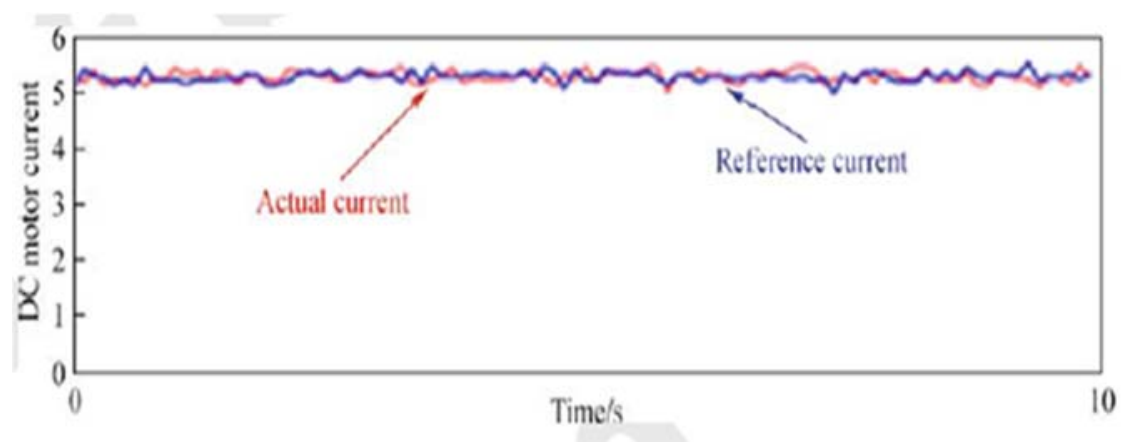

Figure 18. Actual current vs. Reference current

\section{RESULTS}

The experimental set-up is run under different wind speeds for comparison of power speed characteristics of real WT and designed WTE. Initially, the set up is run under a constant wind speed of $6 \mathrm{~m} / \mathrm{s}$ with the balanced three-phase load applied on the generator. To obtain power versus speed characteristics of the WTE, this process is repeated for different wind speeds. Figure 19 illustrated the power-speed features of WTE and WT. dot values represent the experimental measurement whereas solid line depicts the theoretical calculations of the wind turbine. There is a right degree of agreement between the measured values and calculated values as observed in the Figure 19. The performance assessment of actual (power, current) and reference (power, current) are illustrated in the Figure 20 and Figure 21. It is be depicted from the results that hardware in loop simulator efficiently reproduces the WT characteristics.

The experimental results of the test rig using the steady state spectra analysis were benchmarked with the research done at Durham University and University of Manchester UK [25-28]. Table 2 contains the specifications of the test rigs. The WTE was run up to the required super-synchronous speed using the HIL simulator at the constant wind speed of $7 \mathrm{~m} / \mathrm{s}$. Despite different levels specifications as tabulated in Table 2 , the current spectra is presented in Figure 18 [18-21], Figure 19 [18-21] and Figure 20 suggest similar spectral content. With the fundamental frequency and 3rd harmonic, frequencies ' $c$ ' and ' $d$ ' are associated. These frequencies are steady in all the machines. Machine dependent frequencies ' $a$ ' and ' $b$ ' and frequencies ' $e$ ' and ' $\mathrm{f}$ ' also presents the alike results notwithstanding different operating environments.

Int J Pow Elec \& Dri Syst, Vol. 10, No. 2, June 2019 : 971 - 986 


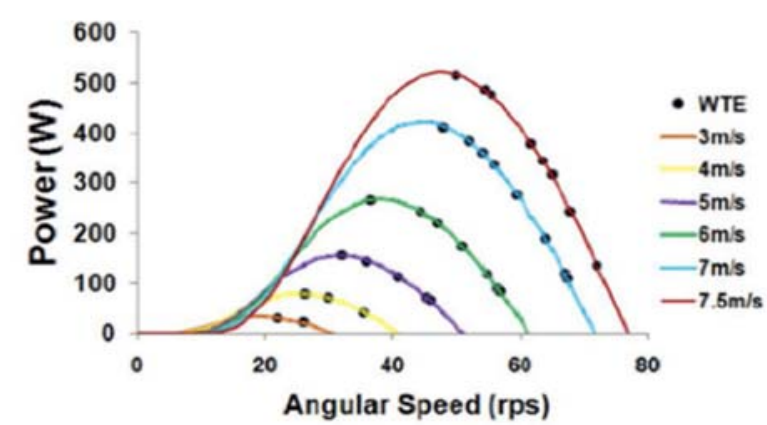

Figure 19. Power speed characteristics of WTE

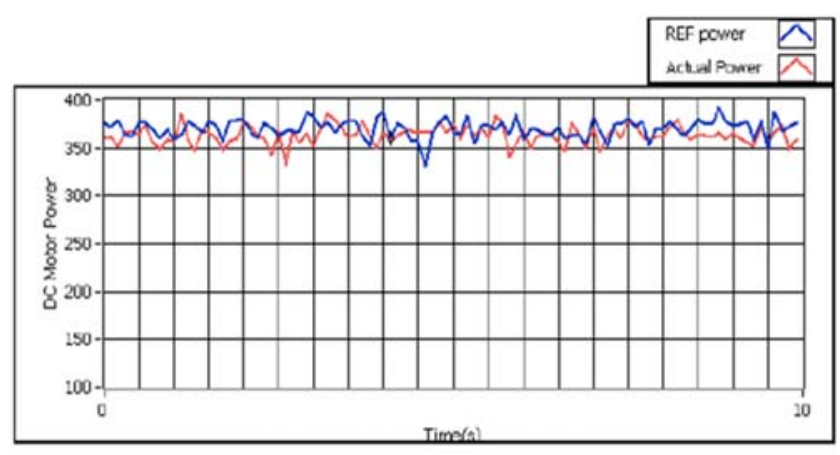

Figure 20. Reference and actual power comparison for a constant wind speed of $7 \mathrm{~m} / \mathrm{s}$

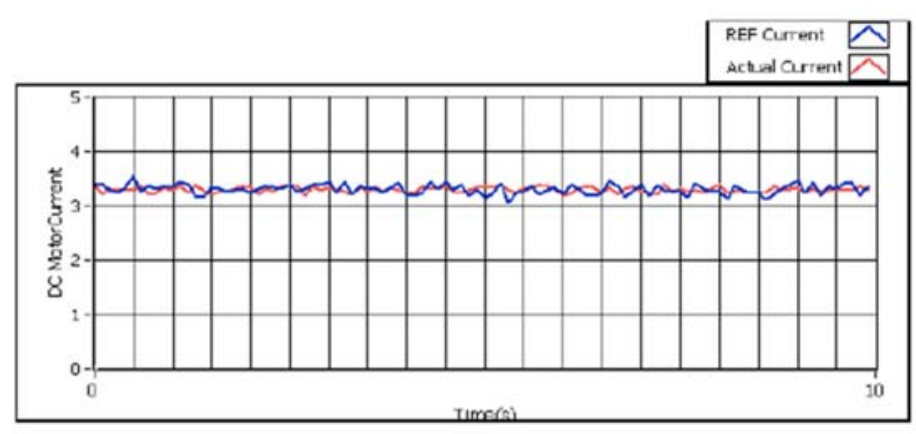

Figure 21. Reference and actual current comparison for a constant wind speed of $7 \mathrm{~m} / \mathrm{s}$

Table 2. Specification of the test rigs

\begin{tabular}{|c|c|c|c|c|}
\hline \multicolumn{2}{|c|}{ Parameters } & Manchester & Durham & NITK \\
\hline Generator & Type & DFIG or WRIG $30 \mathrm{KW}$ & WRIG $30 \mathrm{KW}$ & SCIF $1.5 \mathrm{KW}$ \\
\hline & No. of poles & 4 & 4 & 4 \\
\hline & Rotor resistance, $\Omega$ & 0.07 & 1.2 & 2 \\
\hline & Converter & Back-to-back, $8 \mathrm{kHz}$ Switching & None & None \\
\hline DC Motor & Driving motor (DC) & $40 \mathrm{~kW}$ constant Speed & $54 \mathrm{~kW}$ variable Speed & $2.5 \mathrm{KW}$ \\
\hline Grid connection & & Direct or via Variac & Direct & None \\
\hline Gearbox & & None & 5:1 helical & None \\
\hline Data & Hardware & Precision oscolloscope & NI Lab VIEW & NI Lab VIEW \\
\hline Acquisition & Sampling frequency, $\mathrm{kHz}$ & 2 & 5 & 2 \\
\hline MATLAB FFT analysis & & $0-500 \mathrm{~Hz}$ & & $0-500 \mathrm{~Hz}$ \\
\hline
\end{tabular}




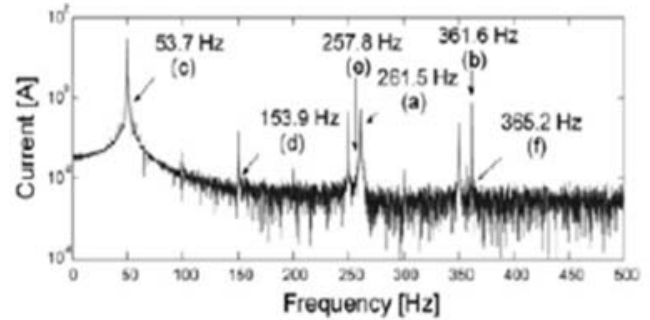

Figure 22. Current spectra of test-University of Manchester

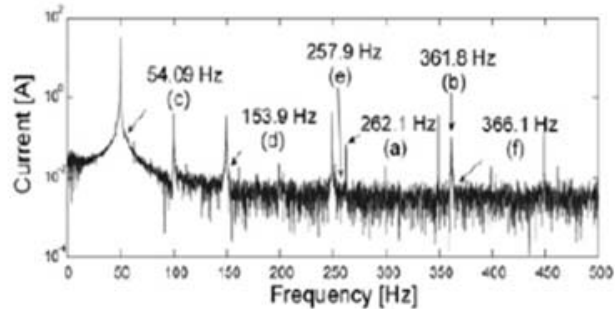

Figure 23. Current spectra of test rig - Durham University

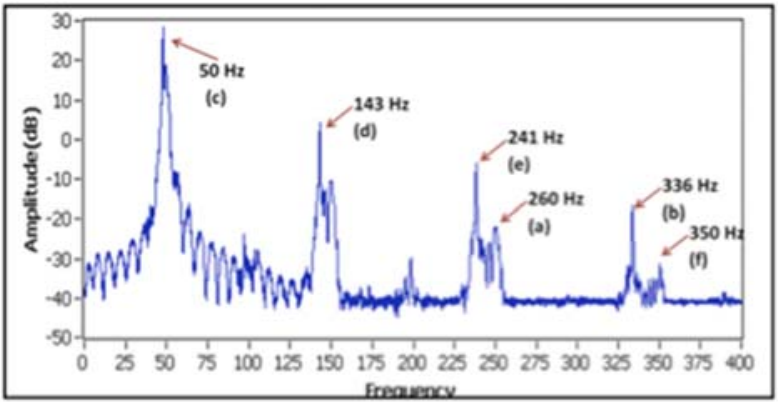

Figure 24. Current spectra of test rig made in the lab

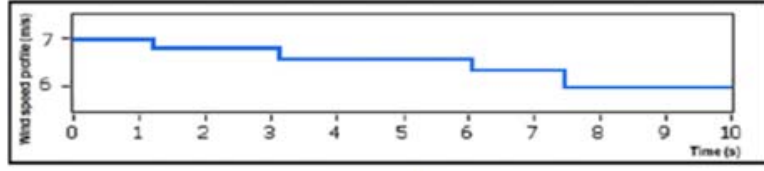

(a)

Speed

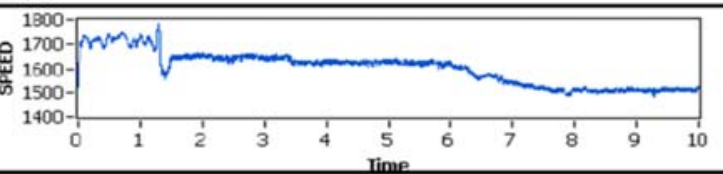

(b)

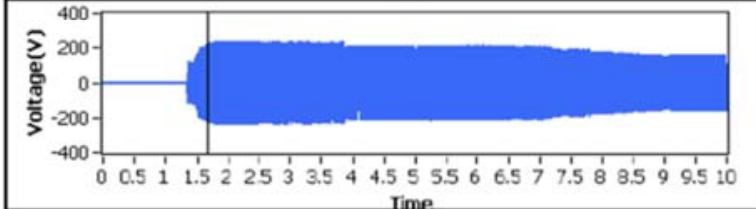

(c)

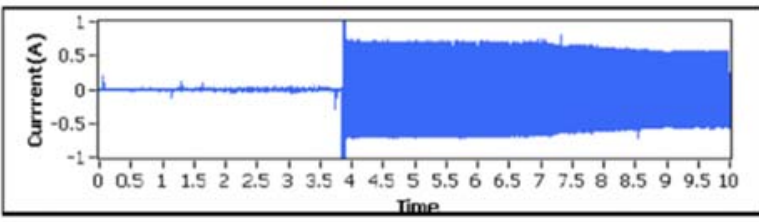

(d)

Figure 25. (a) wind profile (b) Shaft speed (c) terminal voltage (d) Generated current 
As presented in the Figure 25, varying wind profile from 6 to $7 \mathrm{~m} / \mathrm{s}$ is applied using the HIW simulator to analyze the dynamic behavior. Shaft speed of the WT, terminal voltage and generated current follows the wind profile as presented in the Figure 25. This result prove the validity of HIL simulator.
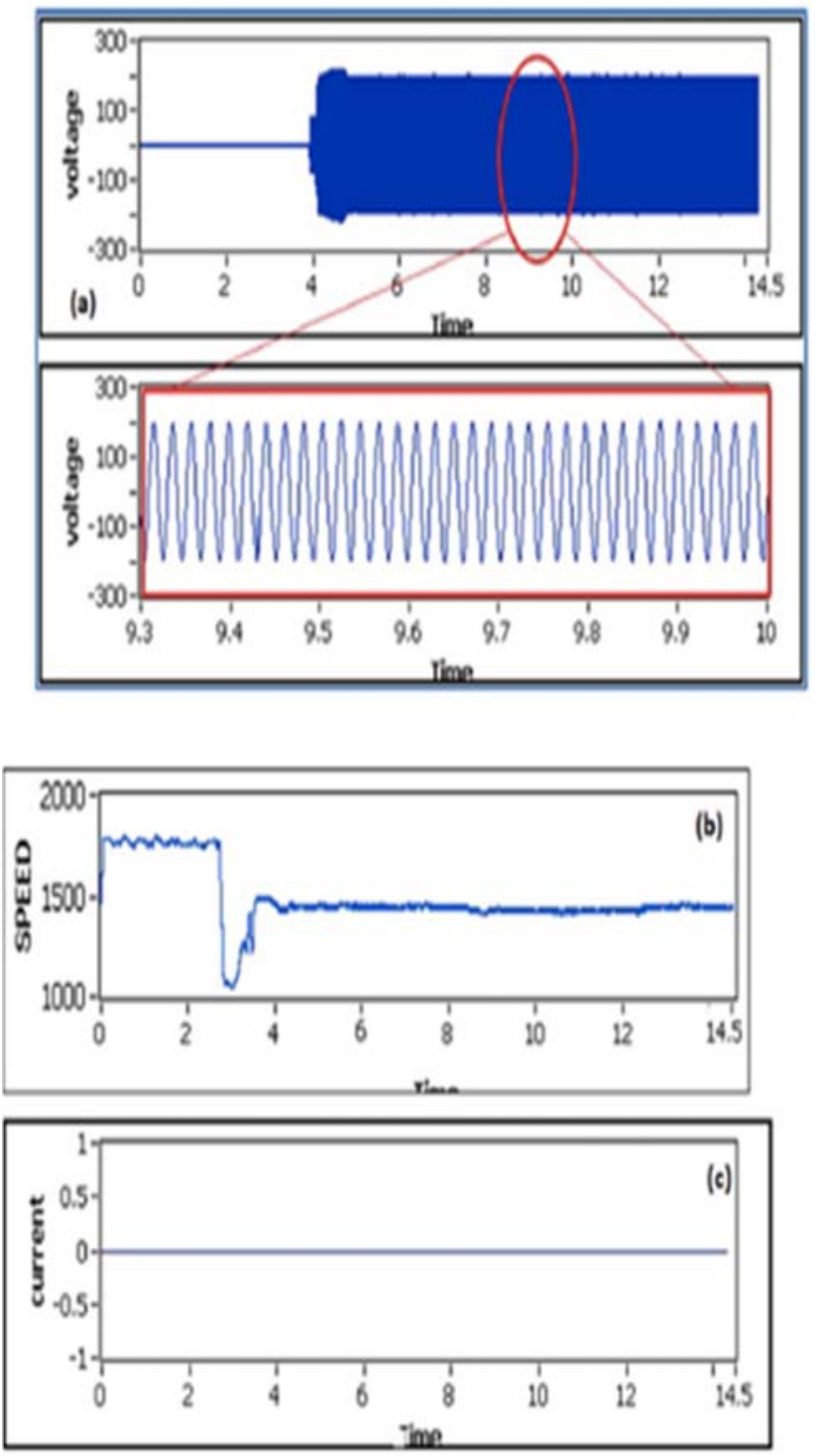

Figure 26. (a) terminal voltage (b) shaft speed (c) line current- At a constant wind speed healthy conditions 

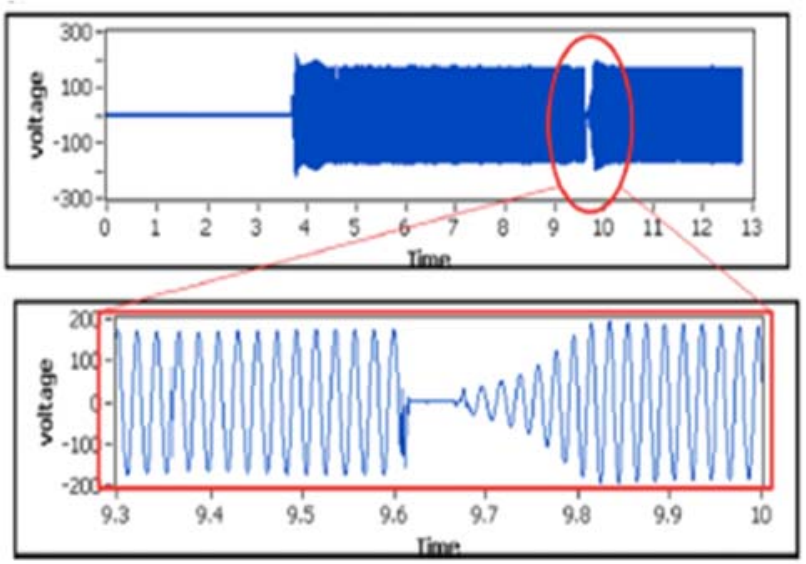

Figure 27. Terminal voltage with short circuit fault

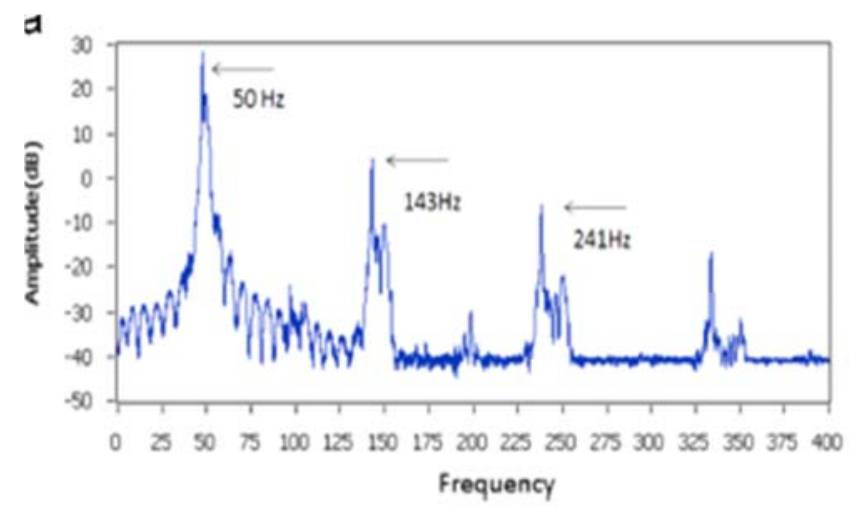

Figure 28. The power spectrum of generated voltage in healthy conditions at constant wind speed

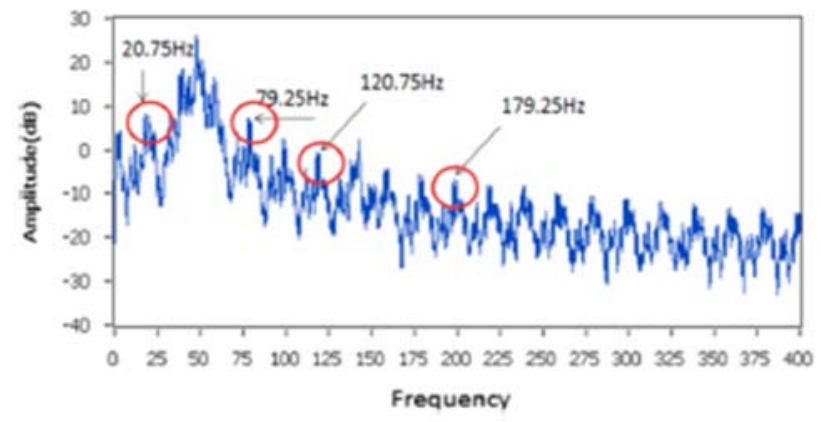

Figure 29. Power spectrum of voltage in faulty conditions at constant wind speed

Phase to phase short circuit fault through a resistor was initiated using the HIL simulator. Terminal voltage contains the unique set of frequencies which are again further analyzed in the HIL simulator. Figure 26 presents the terminal voltage, shaft speed, and the generated current. This test was done at no load and constant wind speed. As illustrated in the Figure 26, generated voltage is $220 \mathrm{~V}$, shaft speed remains constant at 1480 RPM whereas generated current is negligible because of no-load. Figure 27 presents the terminal voltage when short circuit fault is introduced. Figure 28 presents the power spectrum of voltage in the healthy 
conditions in which odd harmonics (i.e. 1st, 3rd, 5th), at $50 \mathrm{~Hz}, 143 \mathrm{~Hz}$ and $241 \mathrm{~Hz}$ are most evident. In faulty condition, with slip $=0.22$, sidebands at $20.75 \mathrm{~Hz}, 79.25 \mathrm{~Hz}, 20.75 \mathrm{~Hz}$ and $179.25 \mathrm{~Hz}$ around first and third harmonics are quite obvious as shown in Figure 29 which confirms the validity of short circuit fault and HIL simulator.

\section{CONCLUSION}

For WT testing, the development of wind turbine simulator is presented. The developed simulator was implemented by low-cost data acquisition devices and other controllers and developed in the LabVIEW.Wind speed can be easily programmed based on the manual setup or recorded wind speed data. The benefits of the simulators are that various WT's and wind profiles can be integrated as required in the software and it comprises the data acquisition to verify the algorithms and exhibit the parameters. The system could deliver all crucial parameters of the WT system such as wind speed, torque coefficient, output torque, output power, tip speed ratio, and power coefficient. The experimental result validates the performance of the HIL systems both under steady-state and dynamic conditions. The power curves which follows the WT features shows the good operations of HIL simulator. Stator winding faults are detected using the power spectrum analysis. This system would be quite useful for the condition monitoring of wind turbines. Simplicity, real-time interfacing, and user controls allow HIL simulator for practical use

\section{REFERENCES}

[1] J. Ribrant and L. Bertling, "Survey of failures in wind power systems with focus on Swedish wind power plants during 1997-2005," IEEE Power Engineering Society General Meeting, vol. 22, pp. 167-173, 2007.

[2] Tavner PJ, Faulstich S, Hahn B, van Bussel GJW. Reliability \& availability of wind turbine electrical \& electronic components. Eur Power Electron J, vol. 20(4), 2011.

[3] Kamel R M., "Effect of wind generation system types on micro-grid (MG) fault performance during both standalone and grid connected modes", Energy Conversion and Management, vol. 79: pp. 232-245, 2014.

[4] S. Faulstich, P. Lyding, and B. Hahn, "Electrical subassemblies of wind turbines- a substantial risk for the availability," European Wind Energy Conference 2010, Warsaw, Poland, 2010.

[5] Seshadrinath J, Singh B, Panigrahi B K. "Single-turn fault detection in induction machine using complex-waveletbased method", IEEE Transactions on Industry Applications, Vol. 48(6), pp. 1846-1854, 2012

[6] Gandhi A, Corrigan T, Parsa L. "Recent advances in modeling and online detection of stator interturn faults in electrical motors", IEEE Transactions on Industrial Electronics, Vol. 58(5), pp. 1564-1575, 2011.

[7] AttouiI,Omeiri A."Modeling,control and fault diagnosis of an isolated wind energy conversion system with a selfexcited induction generator subject to electrical faults", Energy Convers Manag, vol. 82, pp. 11-26, 2014.

[8] Yang W. "Condition monitoring the drive train of a direct drive permanent magnet wind turbine using generator electrical signals", Journal of Solar Energy Engineering, Vol. 136(2), pp. 021008, 2014

[9] N. C. Sahoo, A. S. Satpathy, N. K. Kishore, and B. Venkatesh, "D.C Motor Based Wind Turbine Emulator Using LabVIEW for Wind Energy Conversion System Setup in Laboratory," International Journal of Electrical Engineering Education, vol. 50, no. 2, pp. 111-126, 2013.

[10] W. Yang, P. J. Tavner, C. J. Crabtree, and M. Wlikinson, "Cost-effective condition monitoring for wind turbines," IEEE Trans. Ind. Electron, vol. 57, no.1, pp. 263-271, Jan 2010.

[11] S. Djurović, C. J. Crabtree, P. J. Tavner, and A. C Smith, "Condition Monitoring of Wind Turbine Induction Generators with Rotor Electrical Asymmetry," IET Renewable Power Generation, vol. 6, no. 4, pp. 207-216, 2012.

[12] F. V. Santos, M. R. Guasp, H. Henao, and M.P.-Sanchez, "Diagnosis of rotor and stator asymmetries in woundrotor induction machines under nonstationary operation throughthe instantaneous frequency," IEEE Trans. Ind. Electron., vol. 61, no. 9, pp. 4947-4959, 2014.

[13] X. Gong and W. Qiao, "Current-based mechanical fault detection for direct-drive wind turbines via synchronous sampling and impulse detection," IEEE Trans. Industrial Electronics, vol. 62, no. 3, pp. 1693-1702, Mar 2015.

[14] V. C.-Alarcon, J. A.Daviu, A. Haavisto, and A. Arkkio, "Particle Filter-based Estimation of Instantaneous Frequency for the Diagnosis of Electrical Asymmetries in Induction Machines", IEEE, vol. 63, no. 10, pp. 2454 2463, 2014.

[15] Steurer, M., Bogdan, F., Ren, W., Sloderbeck, M., \& Woodruff, S. "Controller and power hardware-in-loop methods for accelerating renewable energy integration”, In Power Engineering Society General Meeting. IEEE (pp. 1-4), 2007.

[16] Ugur Sancar, Aykut Ozgun Onol, Ahmet Onat, Serhat Yesilyurt, "Hardware-in-the-Loop Simulations and Control Design for a Small Vertical Axis Wind Turbine" 2015 XXV International Conference on Information, Communication and Automation Technologies (ICAT) October 29 - October 31, 2015

[17] M. Monfared, H. Kojabadi, and H. Rastegar, "Static and dynamic WT simulator using a converter controlled D.C motor," Renewable Energy, vol. 33, no. 5, pp. 906-913, 2008.

[18] M. Chinchilla, S. Arnaltes, and J. L. R. Amenedo, "Laboratory set-up for Wind Turbine Emulation," IEEE International Conference on Industrial Technology (ICIT), Hammamet, Tunisia, pp. 553-557, Dec 2004. 
[19] Himani and Ratna Dahiya," Modeling and Development of Wind Turbine Emulator for the Condition Monitoring of Wind Turbine", International Journal of Renewable Energy Research, Vol.5, No.2,pp-591-597,2015

[20] Jaime Castell, Jose. M. Espí, and Rafael García-Gil, "Development details and performance assessment of a Wind Turbine Emulator," Renewable Energy, vol. 86, pp. 848-857, February 2016.

[21] M. Chinchilla, S. Arnaltes, and J. L. R. Amenedo, "Laboratory set-up for Wind Turbine Emulation," IEEE International Conference on Industrial Technology (ICIT), Hammamet, Tunisia, pp. 553-557, Dec 2004.

[22] F. Martinez, C. Herrero, and S. de Pablo, "Open loop wind turbine emulator," Renewable. Energy, vol. 63, no. 0, pp. 212-221, 2014.

[23] Himani and Ratna Dahiya, "Condition Monitoring of Wind Turbine for Rotor Fault detection Under Nonstationary Conditions" Ain Shams Engineering Journal, Elsevier,https://doi.org/10.1016/j.asej.2017.04.002

[24] Himani and Ratna Dahiya, "Development and testing of control strategies of D.C motor for stand-alone wind energy conversion system", In: 2015 2nd International Conference on Recent Advances in Engineering \& Computational Sciences (RAECS),PU Chandigarh; pp. 1-6(2015)

[25] W. Yang, P. J. Tavner, C. J. Crabtree, and M. Wlikinson, "Cost-effective condition monitoring for wind turbines," IEEE Trans. Ind. Electron, vol. 57, no.1, pp. 263-271, Jan 2010.

[26] Wenxian Yang, Tavner P.J., and Wilkinson M., "Wind turbine condition monitoring and fault diagnosis using both mechanical and electrical signatures," International Conference on Advanced Intelligent Mechatronics, 2008. IEEE/ASME , pp. 1296 - 1301, 2008.

[27] W. Yang, P. J. Tavner, C. J. Crabtree, Y. Feng, and Y. Qiu, "Wind Turbine Condition Monitoring: Technical and Commercial Challenges," Wind Energy, vol. 17, no. 5, pp. 673-693, 2014.

[28] W. Yang, P. J. Tavner, and M. R Wilkinson, "Condition Monitoring and Fault Diagnosis of a Wind Turbine Synchronous Generator Drive," IET Renewable Power Generation, vol. 3, no. 1, pp. 1-11, 2009.

[29] Himani and Ratna Dahiya , "Development of Wind Turbine Emulator for Stand-alone Wind Energy Conversion System" In 6th IEEE International Conference on Power Systems, 2016 (ICPS 2016) 4-6 March 2016., Indian Institute of Technology Delhi, 2016.

Int J Pow Elec \& Dri Syst, Vol. 10, No. 2, June 2019 : 971 - 986 